\title{
Symptomatic Intracerebral Hemorrhage Complicating Intra-Arterial Mechanical Thrombectomy in Acute Ischemic Stroke
}

\author{
Muhammad Yunus Amran*, Ashari Bahar \\ Division of Interventional Neurology and Neuroendovascular Therapy, Department of Neurology, Faculty of Medicine, \\ Hasanuddin University. Brain Centre, Dr. Wahidin Sudirohusodo General Hospital and Hasanuddin University Teaching \\ Hospital. Jl. Perintis Kemerdekaan KM 11, Makassar, South Sulawesi, 90245, Indonesia
}

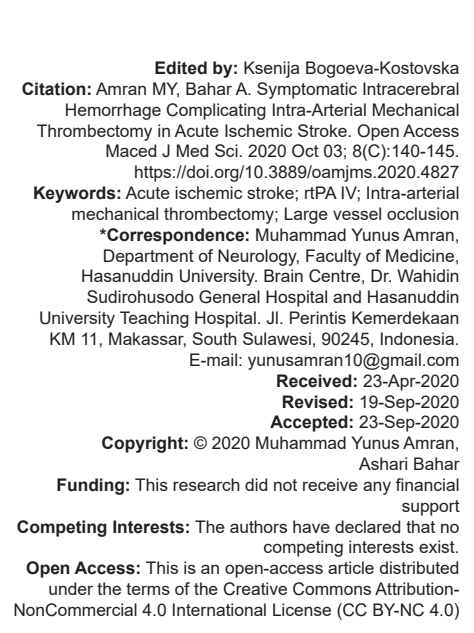

\section{Abstract}

BACKGROUND: Acute ischemic stroke (AIS) is the most common type of stroke. The endovascular treatment of AIS depends on stroke subtype, whether caused by large vessel occlusion (LVO) or not. We presented a case of AIS due to LVO that has complication in the form of symptomatic intracerebral hemorrhage $(\mathrm{SICH})$ after an intra-arterial mechanical thrombectomy.

CASE PRESENTATION: An 80-year-old woman was admitted to the emergency department with sudden onset left side weakness since $<1 \mathrm{~h}$ before admission, when the patient had woke up in the morning. The patient had history of hypertension, diabetes mellitus, and dyslipidemia. She also had cardiac disorders in the form of non-valvular atrial fibrillation with $55 \%$ left ventricular ejection fraction (LVEF). Her blood pressure was $148 / 84 \mathrm{mmHg}$, heart rate was 65 beats/minute, respiratory rate was 17 times $/ \mathrm{min}$, and body temperature was $36.2^{\circ} \mathrm{C}$. Glasgow coma scale (GCS) was E3V4M5; National Institutes of Health Stroke Scale (NIHSS) was 15. She had moderate aphasia. Head CT scan did not show any hyper- or hypodens areas and Alberta Stroke Program Early CT score was 10. RAPID automated CT perfusion using Quantitative Software showed that the mismatch volume was $192 \mathrm{ml}$ and the mismatch ratio was 7.4. Endovascular therapy in the form of intra-arterial mechanical thrombectomy was performed, and blood flow in the right internal carotid artery (ICA) was restored with the score of Modified Thrombolysis in Cerebral Infarction $(\mathrm{mTICl})$ was III. Follow-up non-contrast head CT scan was performed and revealed acute infarction with hemorrhagic transformation in the middle cerebral artery (MCA) territory.

CONCLUSION: Early and accurate treatment of AIS is paramount. Endovascular treatment in the form of intraarterial mechanical thrombectomy is the current treatment recommendation in LVO although there is a risk of symptomatic intracerebral hemorrhage, as in this case.

\section{Introduction}

Cerebrovascular disease/stroke is a major health problem and the leading cause of death and disability in the world and in Indonesia. Based on RISKESDAS 2018, there has been an increase in the prevalence of stroke (permil) in Indonesian population aged $\geq 15$ years, in 2013-2018 from $7 \%$ to $10.9 \%$ [1], [2]. Acute ischemic stroke (AIS) is the most common type of stroke with high rate of disability and death [3], [4]. The management of AIS has evolved since the past 20 years. The principle treatment of AIS is intravenous recombinant tissue plasminogen activator (rt-PA) and endovascular therapy using several catheterbased treatment systems [5], [6], [7], [8]. Endovascular treatment of AIS uses minimally invasive protocol with catheter placement through femoral artery puncture. This procedure has several complications, which can potentially worsen the patient's outcome. Complication can be caused by catheter manipulation, micro-wire, and the use of several thrombectomy devices which can damage to the endothelial lining of the cerebral artery. It may also be caused by the presence of micro emboli that are released when an endovascular handler is performed. In this case report, we reported a case of AIS that was treated with intra-arterial thrombectomy (IAT) using several thrombectomy devices with the results of modified thrombolysis in cerebral infarction (mTICl) 3. However, 1 day after IAT the patient developed intracranial hemorrhage in the right middle cerebral artery (MCA) infarction.

\section{Case Report}

An 80-year-old woman was admitted to the emergency department with complaints of weakness in the left side of her body since less than an hour before admitted. The weakness was developed suddenly after she woke up in the morning. The patient also complained left facial cramp. She had history of hypertension, diabetes mellitus, and dyslipidemia. She also had history of non-valvular atrial fibrillation with left ventricular 
ejection fraction (LVEF) of $55 \%$ and routinely consumed Rivaroxaban $15 \mathrm{mg} /$ day. On physical examination, blood pressure was $148 / 84 \mathrm{mmHg}$, heart rate was 65 beats/ minute, respiratory rate was 17 times/minute, and body temperature was $36.2^{\circ} \mathrm{C}$. Neurological examination was significant for somnolence, with Glasgow coma scale (GCS) score was E3V4M5. She had moderate aphasia, left cranial nerve XII paresis, left sided hemihypesthesia; and left hemiparesis, with National Institutes of Health Stroke Scale (NIHSS) score was 15. The head CT scan results did not show any hyper- or hypodense lesion and the Alberta Stroke Program Early CT score (ASPECTS) was 10 (Figure 1).

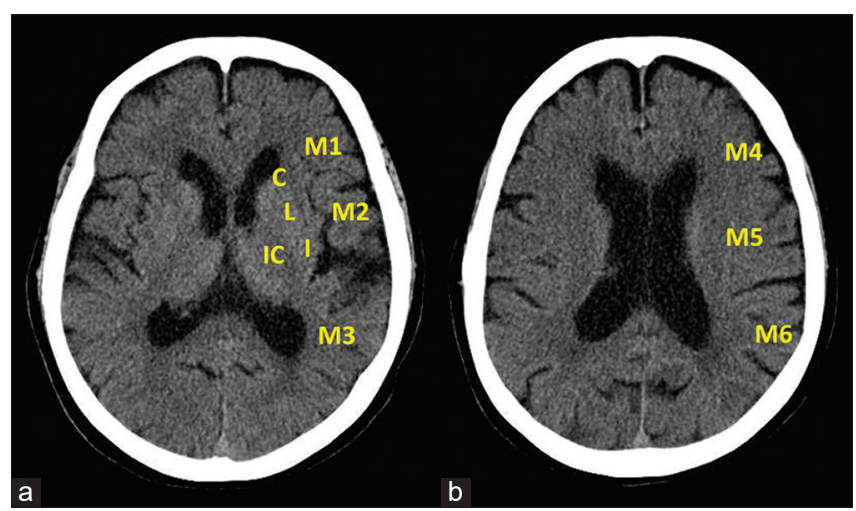

Figure 1: Head CT Scan. (a) Axial/ Basal Ganglia view. No hypodense or hyperdense appear on the axial section (basal ganglia level); (b) Axial/ Ganglion Margin view. No hypodense or hyperdense appear on the axial section (ganglion margin level). (M1-M6: Cortical region, C: Caudate, L: Lentiformis, IC: Internal Capsules, I: Insular Ribbon)

Automated CT perfusion RAPID using Quantitative Software showed that the volume mismatch was $192 \mathrm{ml}$ while the ratio mismatch was 7.4 (Figure 2).

The RAPID ASPECTS score was also 10 (Figure 3). CT brain perfusion showed a large area of potentially salvageable ischemia in the right MCA territory with small infarct core (Figure 4) and CT angiography revealed right internal carotid artery stenosis (Figure 5).
After several neuroimaging examinations were carried out, an endovascular procedure in the form of an intra-arterial (IA) mechanical thrombectomy was performed. The result was smooth blood flow in the right internal carotid artery, visible slowing of blood flow in the right external carotid artery, and visible stenosis in the inferior division of the right MCA. Modified Thrombolysis in Cerebral Infarction (mTICI) was III (Figures 6 and 7).

One day after IA Mechanical Thrombectomy, brain magnetic resonance imaging (MRI) and magnetic resonance angiography (MRA) imaging were performed with the result of extensive acute infarction in the territory of the right MCA with hemorrhagic transformation (in the frontal lobe, insula, and basal ganglia). There were small acute infarcts in the right superior frontal (Area of Anterior cerebral artery/ACA) and in bilateral white matters.

The results of MRA showed complete recanalization of the right internal carotid artery (ICA) and its branch (MCA). MR perfusion showed reduction of perfusion in the infarction area, increased cerebral blood volume (CBV) and decreased time-to-peak (TTP) in the area around the infarct zone, suggesting a luxury perfusion. Non-contrast head CT scan was also performed after MRI and the result was acute infarction with hemorrhagic transformation in the right MCA territory (Figure 8). The patient was still aphasic and hemiparesis when she was discharged.

\section{Endovascular Procedures (Intra Arterial Mechanical Thrombectomy)}

Intra-arterial mechanical thrombectomy started with administration of local anesthetics. The right femoral artery was punctured at the Common FemoralArtery (CFA) around the right inguinal fold using $8 \mathrm{~F}$ femoral sheath.

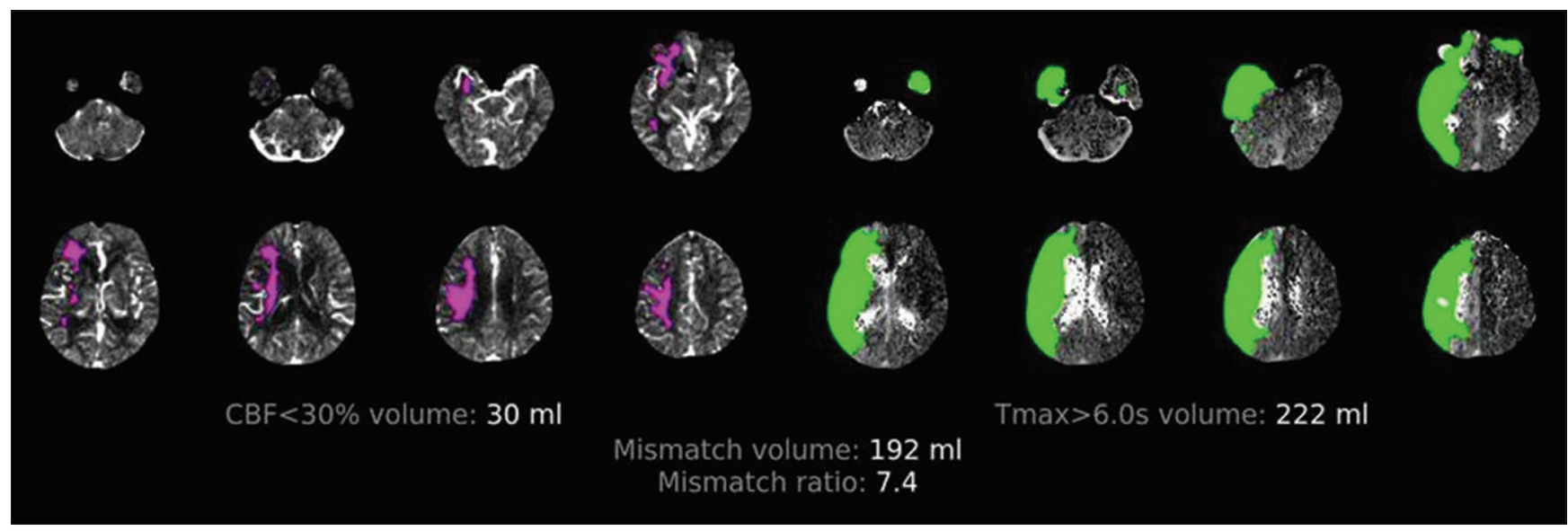

Figure 2: Perfusion maps rapid CT perfusion. Figure 2 shows the unilateral perfusion deficit associated with clinical symptoms from the patient in the form of weakness in the left body. Impaired cerebral blood flow (CBF) area $(<30 \%)$ is $30 \mathrm{ml}$ and time-to-peak concentration (Tmax $>6 \mathrm{~s})$ is $222 \mathrm{ml}$. The mismatch volume (222-30) was $192 \mathrm{ml}$ while the ratio mismatch (222/30) was 7.4 


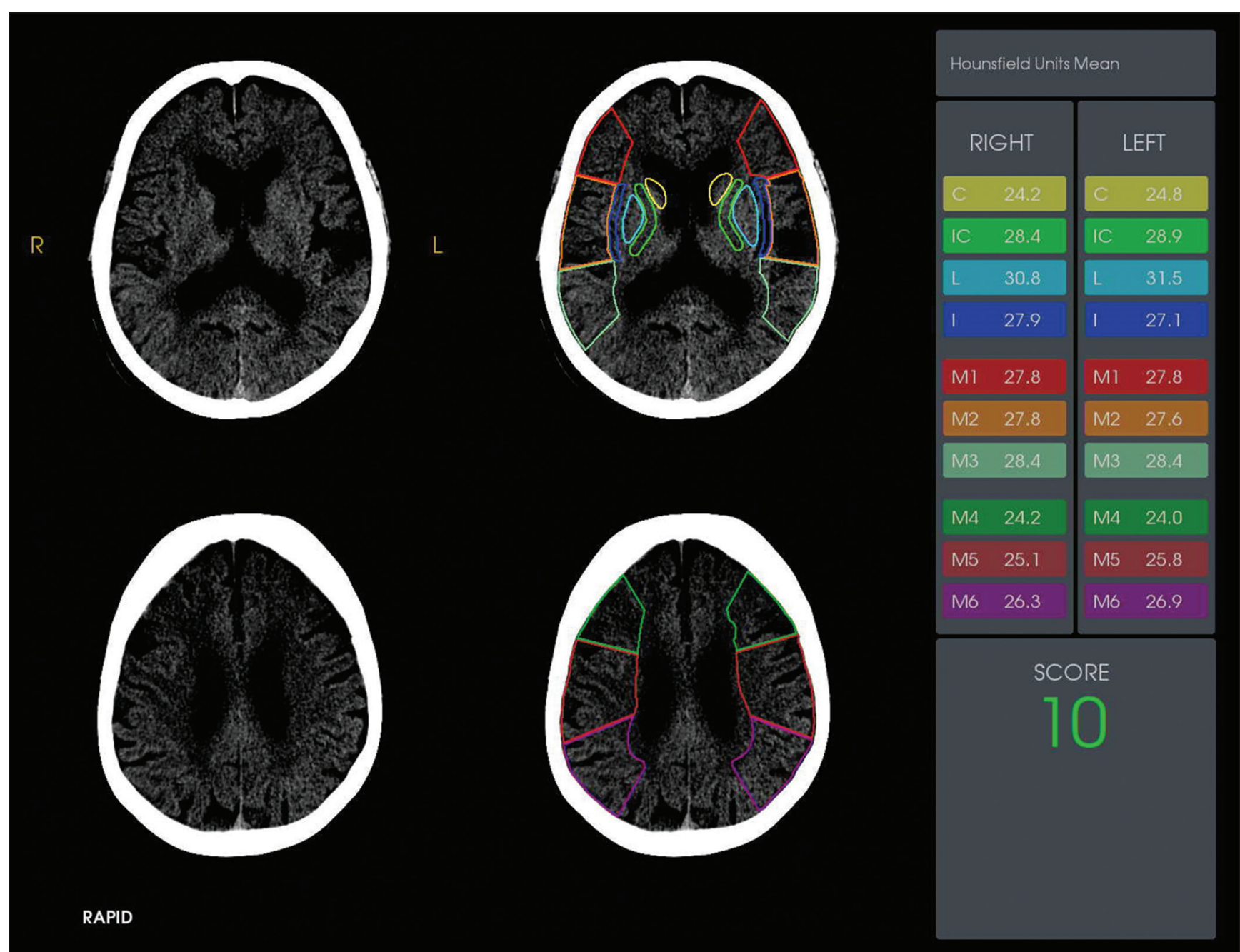

Figure 3: Rapid aspects. There is no visible hyperdense or hypodense area in the M1-M6 and C Caudate area, IC Internal Capsule, L Lentiformis, I Insular Ribbon

After the sheath was placed, 8F Flow Gate Balloon Guide Catheter (OD $0.106 \mathrm{in} / 2.7 \mathrm{~mm}$, ID 0.084in $(6.4 \mathrm{~F} / 2.1 \mathrm{~mm})$, and length of $95 \mathrm{~cm}$ (Stryker Neurovascular) coaxial with 5F Davis catheter (Cook Medical) were used to reach the right ICA. However, due to tortuosity of the aortic arch, $5 \mathrm{~F}$ Davis (Cook Medical) was replaced with 5F HN5 (Cook Medical) and then replaced with $5 \mathrm{~F}$ SIM3, but still failed to pass the aortic arch. The femoral sheath was then replaced with the 8F Flexor ${ }^{\circledR}$ Shuttle ${ }^{\circledR}$ Guiding Sheath (Shuttle-SL; Cook, Bloomington, Ind) coaxial with 5F HN5 (Cook Medical) and then using the 5F Sofia (Microvention, Terumo) intermediate catheter still failed. Then, $5 \mathrm{~F}$ Sofia (Microvention, Terumo) was replaced with $6 \mathrm{~F}$, but still failed. Finally, using 11F femoral sheath, 8F Flow Gate Balloon Guide Catheter (OD 0.106in/2.7 mm, ID 0.084 in $(6.4 \mathrm{~F} / 2.1 \mathrm{~mm})$, length $95 \mathrm{~cm}$, Stryker Neurovascular) coaxial with 5F HN5 (Cook Medical), we were able to reach the right Common Carotid Artery (CCA). Then contrast was injected, and there was right ICA stenosis. We used Microcatheter Prowler Preshaped 45'(Codman) with microguidewire Synchro-14 (Stryker Neurovascular) to remove thrombus; however, it failed and was replaced with microcatheter XT27 (Stryker Neurovascular) and microguidewire Synchro-14 (Stryker Neurovascular). We successfully penetrated the thrombus in the right ICA. A moment before the microwire was directed to the thrombus, balloon flow gate was inflated to hold the blood flow to the right ICA. Then, using $50 \mathrm{cc}$ spoit, aspiration was performed and negative pressure was maintained. After that Trevo retriever stents (Stryker Neurovascular) were used to pull the thrombus. The thrombus was seen in the spoit and in the stent retriever. Recanalization was seen on the right ICA to the right MCA, but we noticed reduction of blood flow in the right external carotid artery and stenosis in the inferior division of the right MCA.

\section{Discussion}

Cerebrovascular disease/stroke is the most common neurologic disorder, with 795,000 new cases annually. Approximately 600,000 cases are first time stroke and around 185,000 cases are recurrent stroke. AIS is the most common type of stroke. One 


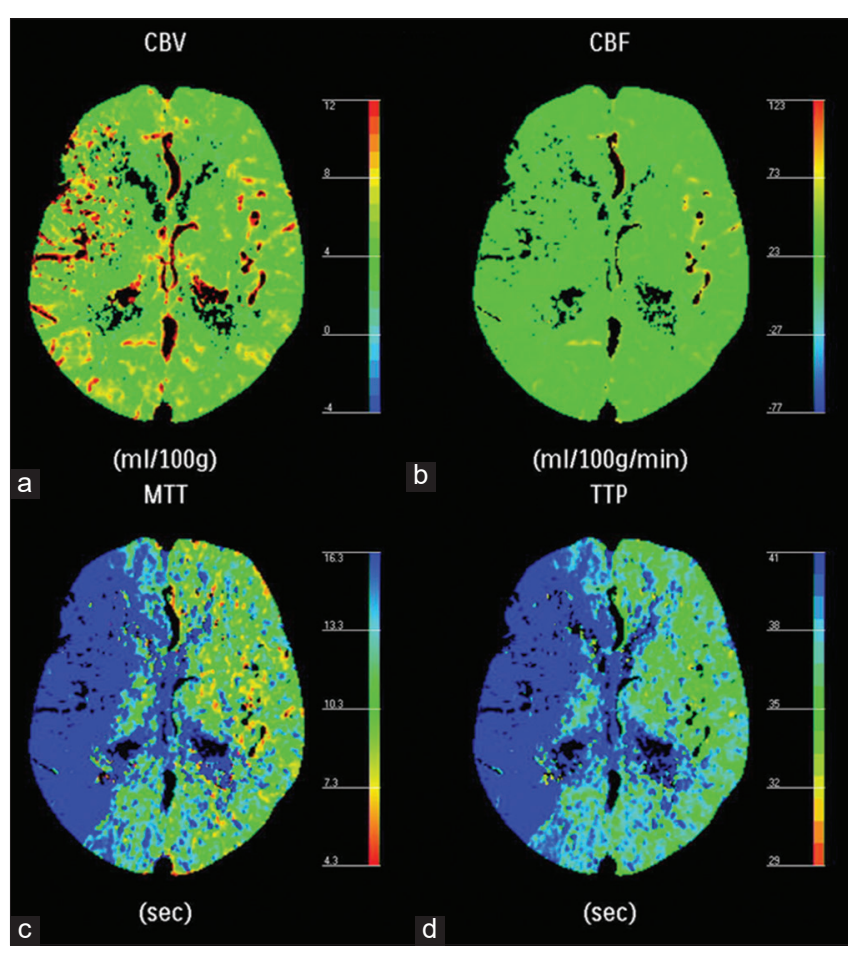

Figure 4: CT Brain Perfusion. (a) Cerebral Blood Volume (CBV), a small infarct core appeared in the right hemisphere; (b) Cerebral Blood Flow (CBF) shows a small area of infarct core in right hemisphere; (c) Mean Transit Time (MTT), a large MTT defect within the right MCA territory; (d) Time-to-peak (TTP), a wide TTP defect within the right MCA territory

of the major independent risk factor for stroke is atrial fibrillation, which can increase the risk of stroke by 5 times [9]. The treatment of AIS has evolved, started in 1995 with the administration of recombinant tissue plasminogen activator (rt-PA) in AIS patient with $<3 \mathrm{~h}$ onset [5]. However, recent studies showed that rt-PA is not effective in the case of large cerebral blood vessels occlusion /LVO [10], [11]. In this case, the patient had a stroke with $<3 \mathrm{~h}$ onset. The neuroimaging examination showed thrombus in the right ICA, in accordance with LVO; thus, rt-PA was not given in this patient.

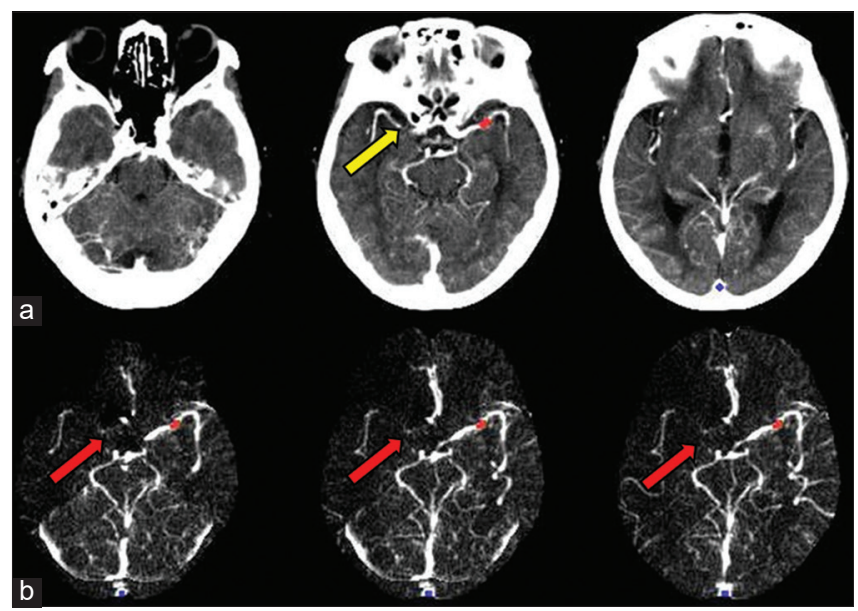

Figure 5: CT Angiography. (a) Thrombus seen in the distal right internal carotid artery (yellow arrow); (b) Bolus Time of contrast did not show contrast flow to the right internal carotid artery and did not show collateral from the left cerebral vessel (red arrow)

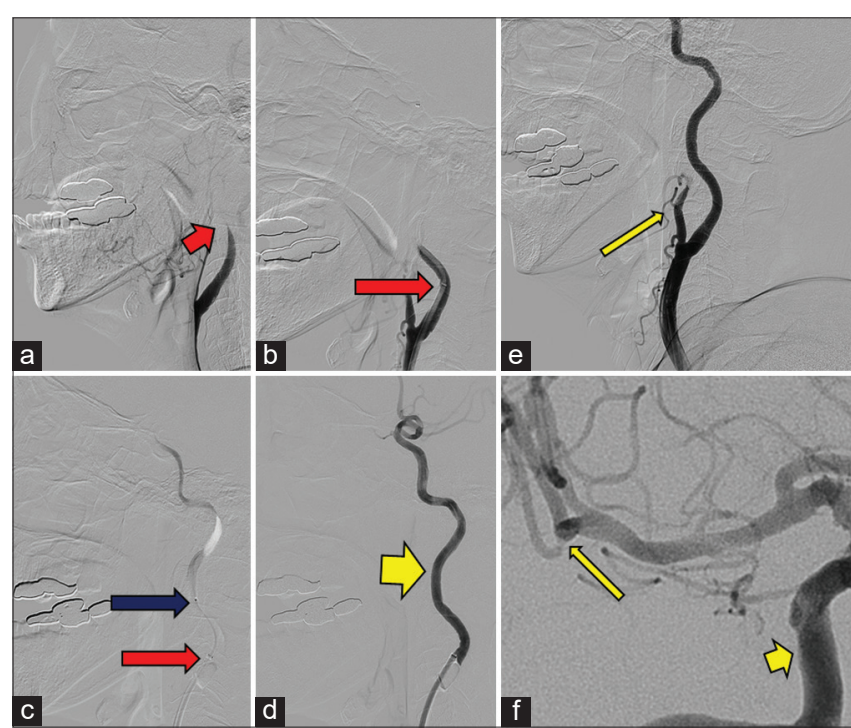

Figure 6: Intra-arterial Mechanical Thrombectomy. (a) Thrombus seen in the distal right internal carotid artery (red arrow); (b) Distal tip of Guiding Catheter Flow Gate (red arrow), (c) Distal tip of Guiding Catheter Flow Gate (red arrow), distal tip of microcatheter XT27 (blue arrow), (d) Recanalization of the right ICA toward distal, (e) Slowing flow to the right external carotid artery (yellow arrow), (f) Visible flow from the right ICA (short yellow arrow) toward to the right MCA and stenosis appears in the inferior division of the right MCA (long yellow arrow)

The development of endovascular intraarterial mechanical thrombectomy, first reported in the early 2000s. After that, many prospective, and multi-center randomized controlled trials (MC RCT) about mechanical thrombectomy were published.

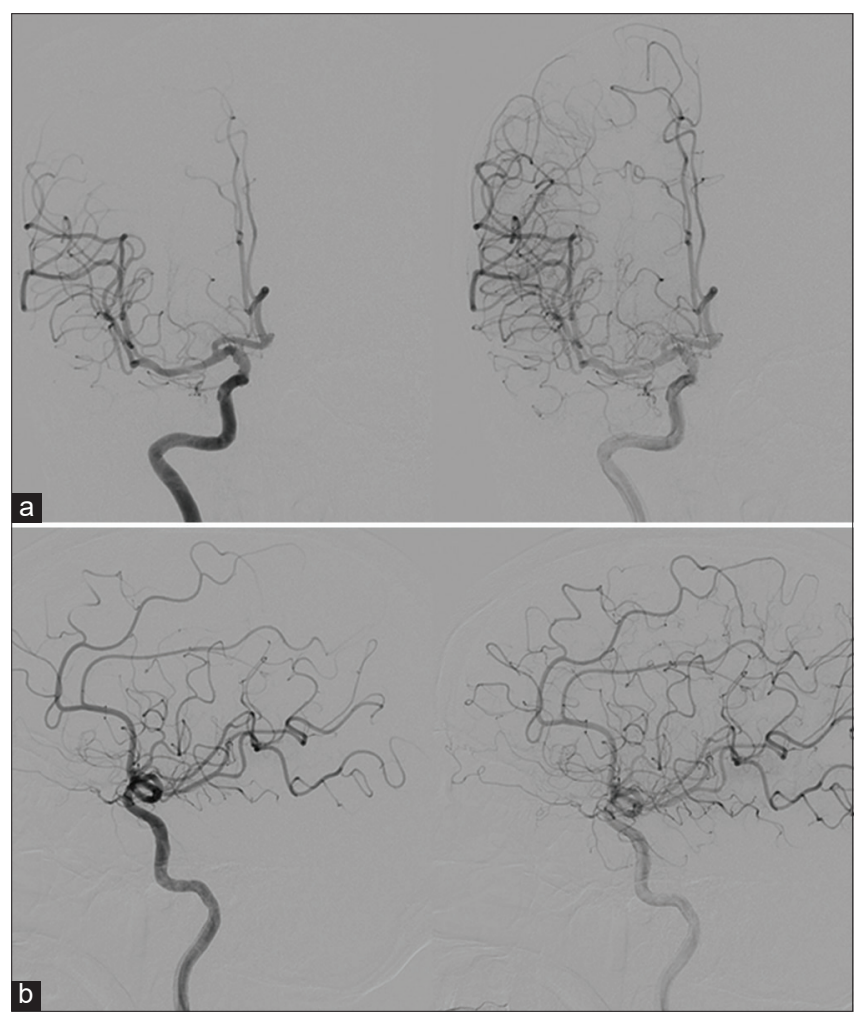

Figure 7: Digital subtraction angiography. (a) Anterior posterior view, visible perfusion throughout the MCA and ACA area, (b) lateral view, visible perfusion throughout the MCA and $A C A$ area 


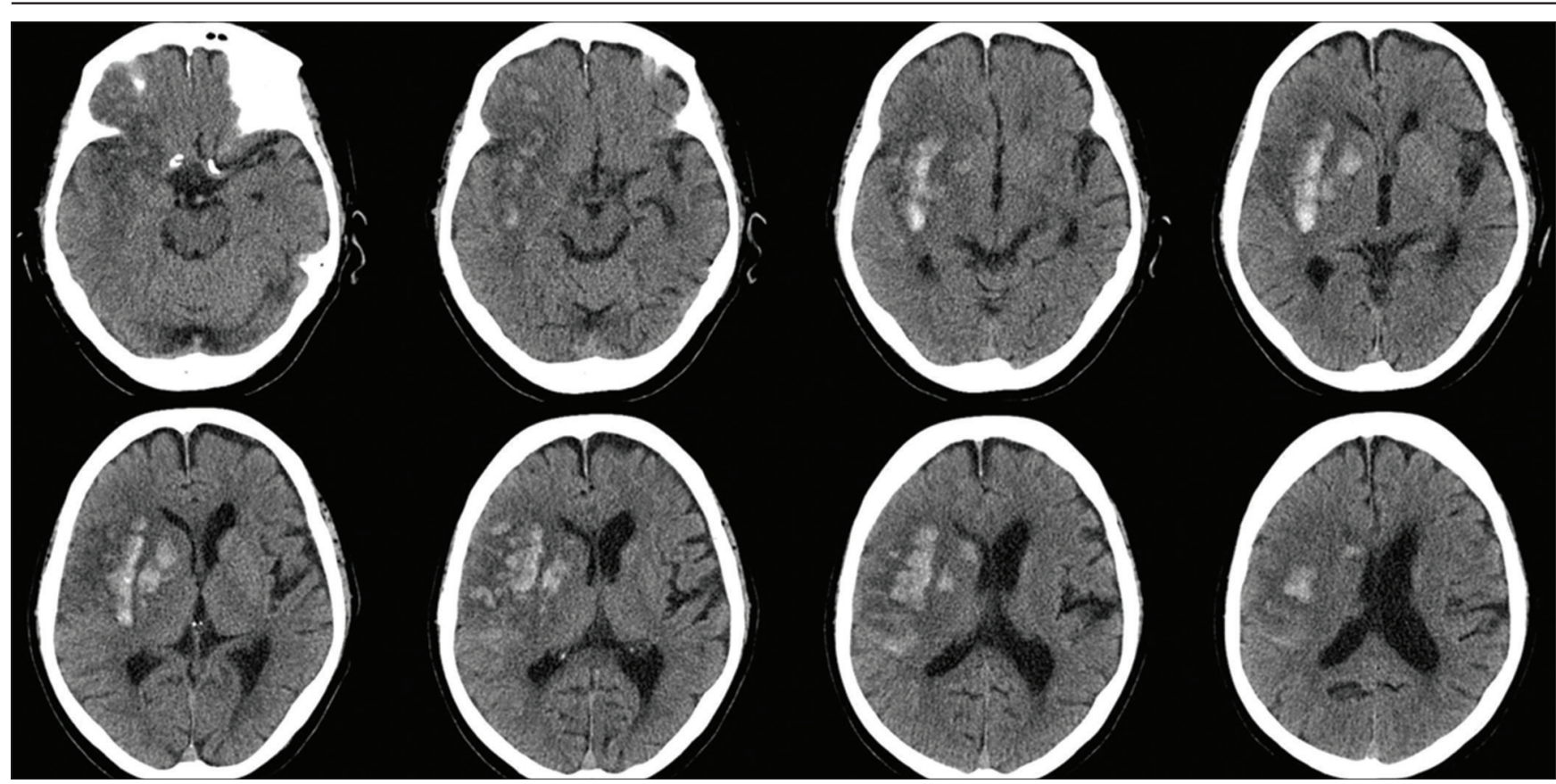

Figure 8: Non-contrast CT head scan. Acute infarction in the right MCA territory with hemorrhagic transformation

These studies confirmed the safety and efficacy of intra-arterial mechanical thrombectomy in the management of AIS, particularly in LVO. In 2013, three prospective MC-RCT studies, Interventional Management of Stroke (IMS) III, Mechanical Retrieval and Recanalization of Stroke Clots Using Embolectomy (MR RESCUE), and Intra-Arterial versus Systemic Thrombolysis for AIS (SYNTHESIS EXP) stated that endovascular therapy was not superior compared to conventional therapy [12], [13], [14]. Then, in early 2018, two MC-RCTs which were DWI or CTP Assessment with Clinical Mismatch in the Triage of Wake-Up and Late Presenting Strokes Undergoing Neurointervention (DAWN) Trial and Endovascular Therapy Following Imaging Evaluation for Ischemic Stroke (DEFUSE 3) trial stated that AIS therapy with endovascular treatment can be beneficial until 16-24 h stroke onset. Those studies also confirmed that intraarterial mechanical thrombectomy was safe and did not associate with significant increase in symptomatic intracranial hemorrhage (sICH) [15], [16]. DEFUSE 3 study used quantitative software in neuroimaging assessments. The inclusion criteria were age between 18 and 85 years, National Institutes of Health Stroke Scale (NIHSS) score $\geq 6$, LVO, ischemic core $<70 \mathrm{ml}$, mismatch volume $\geq 15 \mathrm{ml}$ or DWI volume $<25 \mathrm{ml}$. The exclusion criteria were blood pressure $>185 / 110 \mathrm{mmHg}$, coagulopathy, and the ASPECTS score $<6$ on the head NCCT scan. In this case, the patient was 80 years old, NIHSS 15, LVO in the right ICA, the mismatch ratio was $7.4(>1,8)$, the mismatch volume was $192 \mathrm{ml}$, systolic blood pressure $<185$, no history of coagulopathy, and the ASPECTS score $>6$. Thus, we decided to perform intra-arterial mechanical thrombectomy to this patient.

Intra-arterial mechanical thrombectomy is a recommended treatment for AIS, especially in LVO.
However, this treatment can cause several complications intraprocedural or in the $72 \mathrm{~h}$ post procedural. Intraprocedural complications are injury to the wall of cerebral arteries due to manipulation of thrombectomy devices, hematomas at the CFA puncture site, infection at the puncture site, and complications related to thrombectomy devices such as vasospasm, arterial perforation and dissection, errors in placing the device, symptomatic intracerebral hemorrhage, subarachnoid hemorrhage, pseudo aneurism, or embolization of the distal arteries. There is also additional risk from anesthesia or contrast material injection [17]. In this case, intra-arterial mechanical thrombectomy successfully evacuated the thrombus in right ICA, and resulted in recanalization of the right ICA and its distal branch, ACA, and MCA. However, when performed thrombectomy, it is very difficult to place the catheter in the right CCA due to tortuous aortic arch. Extensive manipulation of thrombectomy devices might cause the release of small thrombus into distal circulation. Despite recanalization, the contrast flow in the right ICA was slow and stenosis was seen in the inferior division of the right MCA. One day after post-therapy, MRI and NCCT head scan showed acute infarction in the right MCA territory with hemorrhagic transformation. The patient still had left-sided hemiparesis and aphasia. Complication arose in the form of intracerebral hemorrhage after intraarterial mechanical thrombectomy and she was treated with a hemorrhage stroke protocol.

\section{Conclusion}

Cerebrovascular disease/stroke is the major cause of death and disability in the world and in 
Indonesia. AIS is the most common type of stroke. Early treatment of AIS, from intravenous rtPA to intraarterial mechanical thrombectomy, is recommended. Complications intra and post-endovascular procedures can occur, but can be minimized by carefully perform the procedure and risk factor assessment.

\section{References}

1. Cardiovascular Diseases (CVDs), World Health Organization; 2019. Available from: https://www.who.int/en/news-room/factsheets/detail/cardiovascular-diseases-(cvds). [Last accessed on 2019 Aug 23].

2. Balitbang Kemenkes RI. Riset Kesehatan Dasar; Riskesdas. Jakarta: Balitbang Kemenkes RI; 2018.

3. Vaartjes I, O'Flaherty M, Capewell S, Capewell S, Kappelle J, Bots M. Remarkable decline in ischemic stroke mortality is not matched by changes in incidence. Stroke. 2013;44:591-7. https://doi.org/10.1161/strokeaha.112.677724

PMid:23212165

4. Feigin VL, Forouzanfar MH, Krishnamurthi R, Mensah GA, Connor M, Bennett DA, et al. Global and regional burden of stroke during 1990-2010: Findings from the global burden of disease study 2010. Lancet. 2014;383:245-55. https://doi. org/10.1016/s0140-6736(13)61953-4 PMid:24449944

5. The National Institute of Neurological Disorders and Stroke rt-PA Stroke Study Group. Tissue plasminogen activator for acute hemisphere stroke. N Engl J Med. 1995;333(24):1581-7. https://doi.org/10.1056/nejm199512143332401

PMid:7477192

6. Chopko BW, Kerber C, Wong W, Georgy B. Transcatheter snare removal of acute middle cerebral artery thromboembolism: Technical case report. Neurosurgery. 2000;46(6):1529-31. https://doi.org/10.1097/00006123-200006000-00046 PMid:10834659

7. Mayer TE, Hamann GF, Brueckmann HJ. Treatment of basilar artery embolism with mechanical extraction device: Necessity of flow reversal. Stroke. 2002;33(9):2232-5. https://doi. org/10.1161/01.str.0000024524.71680.c6 PMid:12215592

8. Yu W, Binder D, Foster-Barber A, Malek R, Smith WS, Higashida RT. Endovascular embolectomy of acute basilar artery occlusion. Neurology. 2003;61:1421-3. https://doi. org/10.1212/wnl.61.10.1421

\section{PMid:14638968}

9. Jauch EC, Saver JL, Adams HP, Bruno A, Connors J, Demaerschalk BM, et al. Guidelines for the early management of patients with acute ischemic stroke: A guideline for healthcare professionals from the American heart association/American stroke association. Stroke. 2013;44(3):870-947. https://doi. org/10.1161/str.0b013e318284056a PMid:23370205

10. Bhatia R, Hill MD, Shobha N, Menon B, Bal S, Kochar P, et al Low rates of acute recanalization with intravenous recombinant tissue plasminogen activator in ischemic stroke: Real-world experience and a call for action. Stroke. 2010;41(10):2254-8. https://doi.org/10.1161/strokeaha.110.592535

PMid:20829513

11. Riedel $\mathrm{CH}$, Zimmermann $P$, Jensen-Kondering $U$, Stingele $R$, Deuschl G, Jansen O, et al. The importance of size: Successful recanalization by intravenous thrombolysis in acute anterior stroke depends on thrombus length. Stroke. 2011;42:1775-7. https://doi.org/10.1161/strokeaha.110.609693

PMid:21474810

12. Broderick JP, Palesch YY, Demchuk AM, Yeatts SD, Khatri P, Hill MD, et al. Endovascular therapy after intravenous tPA versus tPA alone for stroke. N Engl J Med. 2013;368(10):893903. https://doi.org/10.1056/nejmoa1214300 PMid:23390923

13. Kidwell CS, Jahan R, Gornbein J, Alger JR, Nenov V, Ajani Z, et al. A trial of imaging selection and endovascular treatment for ischemic stroke. N Engl J Med. 2013;368(10):914-23. https:// doi.org/10.1056/nejmoa1212793 PMid:23394476

14. Ciccone A, Valvassori L, Nichelatti M, Sgoifo A, Ponzio M, Sterzi R, et al. Endovascular treatment for acute ischemic stroke. N Engl J Med. 2013;368(10):904-13. https://doi.org/10.1056/ nejmoa1213701

PMid:23387822

15. Nogueira RG, Jadhav AP, Haussen DC. Thrombectomy 6 to 24 hours after stroke with a mismatch between deficit and infarct. N Engl J Med. 2018;378(1):11-21. https://doi.org/10.1056/ nejmoa1706442

PMid:29129157

16. Albers GW, Marks MP, Kemp S. Thrombectomy for stroke at 6 to 16 hours with sel ection by perfusion imaging. N Engl J Med. 2018;378(8):708-18. https://doi.org/10.1056/nejmoa1713973 PMid:29364767

17. Balami JS, White PM, McMeekin PJ, Ford GA, Buchan AM. Complications of endovascular treatment for acute ischemic stroke: Prevention and management. Int J Stroke. 2018;13(4):348-61. https://doi.org/10.1177/1747493017743051 PMid:29171362 